\title{
Educação Inclusiva e a Organização da Escola: diálogos críticos sobre o projeto pedagógico ${ }^{1}$ \\ Allan Rocha Damasceno ${ }^{2}$
}

\section{RESUMO}

Educação Inclusiva e a Organização da Escola: diálogos críticos sobre o projeto pedagógico. Com base na Teoria Crítica, analisamos a conjuntura social onde se insere a escola, com vistas ao entendimento de seu processo de (re)organização, tendo como elemento articulador seu Projeto Pedagógico. Este estudo está fundamentado teórico e metodologicamente na Teoria Crítica, com destaque para o pensamento de Theodor Adorno. Vale destacar que outros estudiosos, como Costa e Libâneo são considerados na discussão e análise da organização escolar por intermédio do Projeto Pedagógico, tendo como questão central o atendimento das demandas educacionais dos estudantes com necessidades especiais.

Palavras-chave: Teoria Crítica; Educação Inclusiva; Projeto Pedagógico.

\section{ABSTRACT}

Inclusive Education and School Organization: critical dialogues about pedagogical project. Based on Critical Theory, this work analyzes the social context in which the school is included and its process of (re) organization, using as articulating element its Pedagogical Project. This study is based on Critical Theory's principles and methodologies, as well as on Theodor Adorno's ideas. It is worth mentioning that other scholars, such as Costa and Libâneo are considered in the discussion and analysis of school organization through its Pedagogical Project, presenting as main issue the educational demands of students with special needs.

Key words: Critical Theory; Inclusive Education; Pedagogical Project.

\section{Educação, inclusão e sociedade: diálogos sobre diálogos}

A educação inclusiva é um movimento cultural inserido na dimensão social contemporânea, tendo por pressuposto a democratização tanto da educação quanto da sociedade. Há, nesse movimento, a busca da efetivação de oportunidades de acesso à escola pública por parte dos grupos vítimas da segregação histórica.

1 Este estudo é parte da Tese de Doutorado defendida pelo autor no Programa de Pós-Graduação em Educação da Universidade Federal Fluminense (UFF), sob orientação da Profa ${ }^{a}$. Dra ${ }^{a}$. Valdelúcia Alves da Costa.

2Doutor em Educação (UFF). Professor Adjunto do Instituto de Educação (UFRRJ), atuando no Programa de PósGraduação em Educação, Contextos Contemporâneos e Demandas Populares (PPGEduc). 
Segundo Costa (2004), “a sociedade contemporânea vive um momento cultural favorável à inclusão social e escolar das minorias historicamente excluídas das instâncias sociais e, consequentemente, cresce a demanda por uma sociedade inclusiva”. Nesse sentido, deve-se destacar que esse momento histórico da educação no Brasil evidencia a singularidade de se viver a organização da escola democrática, na qual as diferenças dos estudantes sejam um estímulo para os professores desenvolverem novos métodos/estratégias/meios de ensino que efetivem a aprendizagem de todos.

É fato que, no âmbito da educação, o debate sobre a inclusão vem provocando movimentos no cenário brasileiro e mundial, sendo que um de seus impactos ocorre no campo da educação de pessoas com necessidades especiais. Tal discussão destaca-se no debate das universidades e escolas públicas, uma vez que as mudanças a serem promovidas no sistema educacional demandam esforços, como adaptaçóes arquitetônicas, didático-pedagógicas e curriculares, desenvolvimento de tecnologias assistivas, entre outros.

Podemos entender o movimento de inclusão escolar como ruptura do ideal totalitário presente na sociedade de classes, o que permitirá a experiência do convívio das diferenças no mesmo espaço escolar, por intermédio da educação inclusiva, contrapondo-se à manutenção da segregação que sistematizou escolas diferentes para pessoas diferentes, caracterizando-se, portanto, como oposição à manutenção da segregação, configurada até então como estratégia de manutenção do controle social instituído pelo sistema capitalista.

Observamos, ainda, que no Brasil são incipientes as experiências de organização de escolas que favoreçam a organização de espaços democráticos para o convívio entre os estudantes, independentemente de suas diferenças. Mas esse movimento significa, sobremaneira, a possibilidade de emancipação e autorreflexão crítica sobre a educação segregada e escola especial.

Nossa experiência, balizada nos diálogos com professores que atuam em escolas com propostas inclusivas (o que levaria essas escolas a afirmarem-se democráticas), nos revela que são vários os desafios identificados na organização dessas escolas, ainda mais considerando que essa construção não se dá alienada do sentido e significado de formação, educação e escola assumidos pela sociedade. 
No que se refere ao atendimento dos estudantes com necessidades especiais, dilatam-se os fatores alegados para afirmar a segregação, como falta de preparo profissional, carência de cursos de capacitação e aperfeiçoamento para os professores, inexistência/escassez de adaptações estruturais das escolas, inexistência/escassez de estrutura organizacional que contemple a diversidade dos estudantes, entre outros.

Curiosamente, a identificação da maximização dos desafios postos ao acolhimento da diversidade dos estudantes, também representada e presente nas necessidades educacionais especiais observada em nossas experiências, é que provocou no movimento deste estudo sobre o entendimento das questões desse contexto educacional. Muitas questões nos ocorreram nesse movimento reflexivo sobre a educação 'possível', entre as quais destacamos: é possível a organização escolar que potencialize os processos de aprendizagem onde convivem estudantes com diferenças significativas? Quais seriam as características (pedagógicas, administrativas, arquitetônicas, profissionais) então necessárias a essa organização onde se escolarizam estudantes com diferenças significativas? Todos esses questionamentos sinalizam a problematização da possibilidade de se viver a experiência formativa da escola democrática. Uma escola que pode ser um espaço para além da reprodução social, de autonomia a professores e estudantes.

É importante ratificar que, historicamente, as escolas especiais constituíram-se em espaços estratégicos para a manutenção do distanciamento do convívio social dos estudantes com necessidades educacionais especiais, enfatizando a lógica da exclusão da sociedade de classes. $\mathrm{O}$ momento atual, em prol da educação inclusiva, é de busca da superação da escola especial. Os professores e a comunidade escolar podem agir se desejam promover a (re)organização da escola para tornar-se democrática, atendendo não apenas aos estudantes com necessidades educacionais especiais, mas todos os que se encontram excluídos. Quanto a isso Costa (2005) esclarece que:

\footnotetext{
Diante dessa possibilidade, a questão posta aos profissionais que atuam na educação dos alunos com deficiência é: não é o momento de pensar a própria concepção de educação especial, uma vez que ela contém a ideia de discriminação, de segregação, de barbárie, de exclusão escolar, social e cultural dos alunos com deficiência denominados 'especiais', ou seja, inadaptados, desiguais? Pensar sobre isso pode ser revolucionário, pois 'Aquele que pensa opõe resistência', embora constatando que, para os profissionais dessa área '[...] é mais cômodo seguir a correnteza, ainda que declarando estar contra a correnteza.' (Adorno, 1995, p. 208).
}

Nesse sentido, a superação da escola especial abre caminhos para a organização de escolas inclusivas para estudantes com necessidades especiais nos diversos níveis de ensino. 
De acordo com dados preliminares do Censo Escolar da Educação Básica (MEC, INEP, 2009), atualmente a maior parte das crianças brasileiras ${ }^{3}$ está na escola. Essa é uma conquista recente no Brasil. É preciso pensar essa conquista como social. Nesse contexto, manifesta-se a questão: o que fazer com essa diversidade? A escola tem entre suas funções oferecer a ambiência para o atendimento das diferenças humanas de aprendizagem dos estudantes. Faz-se necessário potencializar cada indivíduo no ato da aprendizagem, com o compromisso do diálogo entre/ com os diferentes estilos e ritmos de aprendizagem.

Os documentos oficiais, nacionais e internacionais, ressaltam os aspectos político-filosóficos a serem assumidos na constituição de uma sociedade inclusiva, onde todos tenham direito à participação, em busca de seu direito ao acesso e permanência na escola. Para tanto, pensamos que um longo caminho ainda deverá ser percorrido. Estudos afirmando a necessidade de pensar a organização da escola para o atendimento educacional e pedagógico das necessidades especiais dos estudantes e seu Projeto Pedagógico ${ }^{4}$, podem conter elementos que possibilitem a efetividade da escola democrática. É nessa esteira que este estudo estabelece sua fundamentação.

Estudo realizado por Damasceno (2006) revelou que, no processo de investigação da formação dos professores atuantes em uma escola municipal da cidade do Rio de Janeiro com experiências de atendimento aos estudantes com necessidades especiais, foi observado que do ponto de vista político-pedagógico, havia uma proposta inclusiva nas ações instituídas pelos professores da escola, embora não se dessem conta disso em suas açóes e ainda não houvesse o Projeto Pedagógico formalizado.

Em decorrência dessa ausência organizacional, práticas dicotomizadas desenvolviam-se nas ações da escola estudada, como por exemplo, a naturalização da coexistência de classes especiais e classes inclusivas, sendo a primeira um espaço de permanência dos estudantes com deficiência até a maioridade. Dessa forma, a classe especial tornara-se um gueto em um ambiente escolar considerado inclusivo. Enquanto os estudantes estão 'acomodados' em espaços escolares segregados, não há o que se questionar. O desafio está justamente em propor uma educação aos estudantes com deficiência para além de espaços segregados.

3 Os dados preliminares do Censo Escolar da Educação Básica 2009 não fazem referência se os estudantes com necessidades especiais estariam incluídos nessas estatísticas. Dados mais recentes analisados por Meletti \& Bueno (2010) confirmam que os estudantes com necessidades especiais não estão incluídos em sua maioria.

4 Neste estudo adotamos a expressão 'Projeto Pedagógico', conforme disposto no Art. 14, Inciso I, da Lei de Diretrizes e Bases da Educação Nacional, n. ${ }^{\circ}$ 9.394/1996. Entretanto, o resultado do processo de planejamento tem recebido várias denominações, como 'Projeto Pedagógico-Curricular', 'Proposta Pedagógica', 'Projeto PolíticoPedagógico', 'Projeto Educativo', 'Projeto da Escola', dentre outras em sua referência. Por entendermos que a dimensão pedagógica não está dissociada da dimensão política do projeto, ratificamos o uso da expressão 'Projeto Pedagógico', aportando-se na Teoria Crítica da Sociedade, sobretudo no pensamento do filósofo Theodor Adorno. 
Portanto, cabe a discussão da questão, sendo possível afirmar que os processos de elaboração/ implementação/avaliação do Projeto Pedagógico escolar podem constituir-se de decisivos momentos de orientação das práticas educativas desenvolvidas e assumidas pela comunidade escolar. Assim, pelo seu processo de elaboração/implementação/avaliação compreende-se também o processo de organização da escola.

Como se pode verificar, na legislação em vigência no Brasil, a participação dos profissionais da educação na elaboração da proposta pedagógica escolar é reconhecida e assumida como prática transformadora, objetivando a constituição de um projeto que seja reconhecido, sendo executado com base em referenciais político-filosóficos definidos pela comunidade escolar e que assumam o compromisso para sua implementação. Contudo, o que observamos é que se tem pouca ou nenhuma visibilidade a participação dos profissionais da educação na elaboração do Projeto Pedagógico da escola.

Em outras palavras, assumir um projeto de escola inclusiva significa romper com a ideologia vigente de que a escola serve exclusivamente à manutenção da lógica dominante, reproduzindo assim as contradições sociais. É possível pensar a escola democrática, desde que atuante com profissionais que assumam autonomamente suas vidas e dirijam todos os seus esforços para tal consecução, como afirmado por Adorno (1995), ou seja, só é possível pensar uma sociedade democrática constituída por indivíduos livre-pensantes. Assim, um projeto de escola democrática nos aponta a possibilidade de uma sociedade igualmente democrática. Daí ser da maior importância o trabalho educativo necessário às mudanças da estrutura escolar vigente.

Nesse sentido, a consolidação de práticas educacionais inclusivas, considerando as demandas de aprendizagem dos estudantes, isto é, o reconhecimento de sua diversidade cultural, cognitiva, sensorial e física, pensar e refletir sobre as diferenças humanas pode ser a 'chave' para a ruptura com o modelo homogeneizador que impõe à escola a manutenção de práticas educacionais desconsiderando essa diversidade.

Para tal, a própria comunidade escolar, com base nas problematizações que serão demandadas no processo de elaboração/implementação/avaliação do Projeto Pedagógico de cada escola, reconhecerá os limites sociais e possibilidades da organização da escola democrática. Contudo, para tal é necessário o desencadeamento de um movimento que problematize e que gere o incômodo em relação ao acolhimento da diversidade cultural e humana. 


\title{
Concepção metodológica: análise à luz da Teoria Crítica
}

Este estudo apresenta como questão central a discussão/problematização da organização da escola na perspectiva da educação inclusiva, com vistas à sua democratização por meio de seu Projeto Pedagógico. Nesse sentido, nos apoiamos na Teoria Crítica, com destaque para o pensamento de Adorno, como também outros estudiosos, como suporte teórico-metodológico deste estudo.

Ao assumir a Teoria Crítica como fundamentação teórico-metodológica deste estudo, com destaque para o pensamento de Adorno e Becker, entendemos que essa teoria constitui-se no próprio método da pesquisa, ou seja, nessa perspectiva não há sentido em qualificar esta pesquisa como quantitativa ou qualitativa, o que segundo a própria Teoria Crítica significaria enclausurar o objeto de estudo. Mas, para além dessa dimensão exclusiva, entender em que dimensão um diálogo entre a Teoria e a Práxis não oportuniza uma (re)significação de olhares para a pesquisa em si.

Sobre este aspecto, esclarece Adorno (1995a):

\begin{abstract}
Até que ponto a questão relativa à teoria e práxis depende da relativa a sujeito e objeto, evidenciase por uma simples reflexão histórica. Ao mesmo tempo em que a doutrina cartesiana das duas substâncias ratificava a dicotomia entre sujeito e objeto, a práxis era apresentada, pela primeira vez, na poesia, como problemática, em virtude de sua tensão frente à reflexão. A razão pura prática, com todo realismo zeloso, é tão desprovida de objeto quanto o mundo é desqualificado para a manufatura e a indústria que o reduzem a material de elaboração e que, por sua vez, não pode legitimar-se senão no mercado. Enquanto a práxis promete guiar os homens para fora do fechamento em si, ela mesma tem sido, agora e sempre, fechada; é por isso que os práticos são inabordáveis, e a referência objetiva da práxis, a priori minada. Até se poderia perguntar se, até hoje, toda práxis, enquanto domínio da natureza, não tem sido, em sua indiferença frente ao objeto, práxis ilusória. Seu caráter ilusório transmite-se também a todas as ações que, sem solução de continuidade, tomam da práxis o velho e violento gesto.
\end{abstract}

A reflexão proposta por Adorno põe em xeque o materialismo histórico cartesiano ao distinguir, em planos distintos, teoria e práxis, como se existissem de forma totalmente independente e não se relacionassem. Nesse sentido, o questionamento à objetividade existente na razão debate o suposto praticismo que impera na lógica fundante racional, ou seja, a análise meramente objetiva de uma realidade complexa pode alienar o próprio objeto de estudo.

Assim, a escolha não por uma práxis metodológica, configurando-se de forma geral em um modelo, muito comum nos estudos que se categorizam como estudo de caso, pesquisa-ação, entre outros, mas sim da relação Teoria-Práxis proposta pela Teoria Crítica, deseja superar, segundo Adorno (1995a): 
O que, desde então, vale como o problema da práxis, e hoje novamente se agrava na questão da relação entre teoria e práxis, coincide com a perda de experiência causada pela racionalidade do sempre-igual. Onde a experiência é bloqueada ou simplesmente já não existe, a práxis é danificada e, por isso, ansiada, desfigurada, desesperadamente supervalorizada. Assim, o chamado problema da práxis está entrelaçado com o do conhecimento.

Nessa perspectiva, a lente que é utilizada para enxergar a realidade pode impedir o que é visto, ou seja, a questão da escolha metodológica de um estudo não se restringe a optar dentre um considerado número de caminhos metodológicos o que se adequou melhor à proposta da pesquisa.

Mas, para além desse movimento, partir da Teoria para entender a Práxis, retornando à primeira para construir conhecimento, nas palavras de Adorno, uma vez que Práxis e Conhecimento são indissociáveis.

\section{A escola e sua organização: diretrizes políticas para sua democratização}

Pensando a organização da escola democrática, defendemos que a reflexão, ao se discutir a organização da escola que atenda à diversidade dos estudantes, opondo-se à segregação histórica de espaços escolares diferentes e sistematizados segundo a ideia de 'capacidade', esta fundamentada em valores amalgamados em preconceitos sobre a concepção de deficiência e da pessoa com deficiência, significando uma educação para a resistência à barbárie. E, sobretudo, uma educação para a experiência, segundo o pensamento de Adorno (1995), inaugurando um momento histórico de possibilidades para a escola. Então, assumindo a concepção de educação apresentada neste estudo, dialogamos com um aspecto componente da diversidade dos estudantes da escola contemporânea: os que possuem necessidades educacionais especiais 5 .

Estudos recentes de Costa (2007) apontam que, para o acolhimento da diversidade dos estudantes com necessidades especiais na escola contemporânea, são necessários esforços que se centralizem, primordialmente, em duas frentes de trabalho:

No que se refere à formação de professores e à inclusão de alunos com necessidades especiais, os dispositivos legais vigentes estabelecem a elaboração e implementação de políticas públicas em educação que promovam movimentos de democratização e inclusão nas escolas públicas

5 Segundo o documento da Política Nacional de Educação Especial na perspectiva da Educação Inclusiva, o conceito de necessidades educacionais especiais, que passa a ser amplamente disseminado a partir da Declaração de Salamanca, ressalta a interação das características individuais dos alunos com o ambiente educacional e social. [...] Assim, a partir dessa conceituação, considera-se pessoa com deficiência aquela que tem impedimentos de longo prazo, de natureza física, mental ou sensorial que, em interação com diversas barreiras, pode ter restringida sua participação plena e efetiva na escola e na sociedade. (p. 8) 
brasileiras por intermédio de: a) programas de formação de professores e demais profissionais da escola; b) organização de escolas inclusivas no enfrentamento e superação da discriminação quanto à matrícula de alunos com necessidades educativas especiais em escolas regulares.

De acordo com a referida autora, para a organização da escola democrática/inclusiva, a organização do trabalho pedagógico deve ser entendida como um dos principais fatores que possibilitará o atendimento das demandas dos estudantes com necessidades educacionais especiais.

Outros estudiosos reforçam o pensamento de Costa, ao reafirmarem que a atenção que deve ser dispensada à organização da escola com vistas ao acolhimento da diversidade presente nas necessidades educacionais especiais é uma questão central no processo de (re)estruturação da escola contemporânea que se deseja democratizar. Nesse caso, Glat e Blanco (2007), tal como Costa, afirmam:

Para tornar-se inclusiva a escola precisa formar seus professores e equipe de gestão, e rever as formas de interação vigentes entre todos os segmentos que a compõem e que nela interferem. Precisa realimentar sua estrutura, organização, seu projeto político-pedagógico, seus recursos didáticos, metodologias e estratégias de ensino, bem como suas práticas avaliativas.

Percebemos a retomada, no pensamento de Glat e Blanco (2007), da necessidade de refletirmos sobre a questão da organização escolar com vistas ao atendimento às necessidades especiais dos estudantes na escola. Ainda reforçam, em tempo, essa concepção quando afirmam que "a proposta de educação inclusiva implica, portanto, um processo de reestruturação de todos os aspectos constitutivos da escola, envolvendo a gestão de cada unidade e dos próprios sistemas educacionais."

Quando nos reportamos à legislação e aos documentos oficiais, encontramos na Declaração Mundial sobre Educação para Todos ${ }^{6}$ o Plano de Ação para Satisfazer as Necessidades Básicas de Aprendizagem aprovada pela Conferência Mundial sobre Educação para Todos, realizada em Jomtien, Tailândia, no período de 5 a 9 de março de 1990, a previsão quanto à organização dos sistemas de educação no atendimento às necessidades educacionais que materializem a educação para todos:

1.3. Definir políticas para a melhoria da educação básica. As estratégias específicas, orientadas concretamente para melhorar as condições de escolaridade, podem ter como foco: os educandos e seu processo de aprendizagem; o

\footnotetext{
6 Este Plano de Ação para Satisfazer as Necessidades Básicas de Aprendizagem deriva da Declaração Mundial sobre Educação para Todos, adotada pela Conferência Mundial sobre Educação para Todos, da qual participaram representantes de governos, organismos internacionais e bilaterais de desenvolvimento, e organizações nãogovernamentais. Fundamentado no conhecimento coletivo e no compromisso dos participantes, o Plano de Ação foi concebido como uma referência e um guia para governos, organismos internacionais, instituições de cooperação bilateral, organizações não-governamentais (ONGs) e todos aqueles comprometidos com a meta da educação para todos.
} 
pessoal (educadores, administradores e outros); o currículo e a avaliação da aprendizagem; materiais didáticos e instalações. Estas estratégias devem ser aplicadas de maneira integrada; sua elaboração, gestão e avaliação devem levar em conta a aquisição de conhecimentos e capacidades para resolver problemas, assim como as dimensões sociais, culturais e éticas do desenvolvimento humano. (1990, p.16)

É possível observar que na Declaração de Jomtien, é definido como política para a melhoria da Educação Básica, o desenvolvimento de ações que objetivem o aperfeiçoamento das condições de escolaridade com base no desenvolvimento de estratégias que foquem o processo de aprendizagem dos estudantes, elencando-se a atuação no âmbito administrativo, ou seja, organizacional, como elemento central nessa construção.

Outro movimento mundial que possibilitou reflexões acerca do acolhimento ${ }^{7}$ dos estudantes com necessidades especiais na escola contemporânea, foi a Declaração de Salamanca e Enquadramento da Ação na Área das Necessidades Educativas Especiais ${ }^{8}$ - Conferência Mundial sobre Necessidades Educativas Especiais: acesso e qualidade, realizada em Salamanca, Espanha, no período de 7 a 10 de junho de 1994.

Nessa Declaração, vários aspectos merecem destaque ao afirmarem a necessidade emergencial de (re)organização da estrutura escolar para o acolhimento das necessidades educacionais especiais dos estudantes. Destacamos, inicialmente, a seguinte disposição (1994):

Acreditamos e proclamamos que:

- os sistemas de educação devem ser planejados e os programas educativos implementados tendo em vista a vasta diversidade destas características e necessidades;

- as crianças e jovens com necessidades educativas especiais devem ter acesso às escolas regulares, que a elas se devem adequar através duma pedagogia centrada na criança, capaz de ir ao encontro destas necessidades.

\footnotetext{
7 Neste estudo, quando adotamos o uso da expressão acolhimento, nos referimos ao conjunto de estratégias pedagógicas e a mobilização de saberes/fazeres profissionais que possibilitam o atendimento das demandas educacionais e pedagógicas dos estudantes com necessidades especiais.

8 Segundo a própria Declaração, em seu preâmbulo, reuniram-se em Salamanca, Espanha, mais de 300 participantes, em representação de 92 governos e 25 organizações internacionais, a fim de promover o objetivo da Educação para Todos, examinando as mudanças fundamentais de políticas necessárias para desenvolver a abordagem da educação inclusiva, nomeadamente, capacitando as escolas para atender todas as crianças, sobretudo as que têm necessidades educativas especiais. A Conferência adotou a Declaração de Salamanca sobre os Princípios, a Política e as Práticas na área das Necessidades Educativas Especiais e um Enquadramento da Ação. Esses documentos estão inspirados pelo princípio da inclusão e pelo reconhecimento da necessidade de atuar com o objetivo de conseguir 'escolas para todos' - instituições que incluam todas as pessoas, aceitem as diferenças, apoiem a aprendizagem e respondam às necessidades individuais. Como tal, constituem uma importante contribuição ao programa que visa à Educação para Todos e à criação de escolas com maior eficácia educativa.
} 
A afirmativa de que os sistemas educacionais devem ser planejados considerando o desenvolvimento de programas educativos que atendam à diversidade dos estudantes, anuncia que a organização é um dos eixos que constituem o movimento de democratização da escola, como afirmado por Costa (2007). Nesse sentido, ainda é reafirmado no texto da Declaração (1994):

- estabelecer mecanismos de planejamento, supervisão e avaliação educacional para crianças e adultos com necessidades educativas especiais, de modo descentralizado e participativo;

- encorajar e facilitar a participação dos pais, comunidades e organizações de pessoas com deficiência no planejamento e na tomada de decisões sobre os serviços na área das necessidades educativas especiais.

E sobre o planejamento, não há dúvida sobre a orientação de que se desenvolva de maneira participativa, ampliando o processo de organização ao descentralizar-se, apontando a participação de outros agentes, como pais e comunidade, no processo da organização escolar.

Nesse sentido, a Declaração de Salamanca ainda ressalta a importância desse trabalho, quando apresenta como condição primária para o acolhimento da diversidade presente no âmbito das necessidades educacionais especiais que "o princípio orientador deste Enquadramento da Ação consiste em afirmar que as escolas devem se ajustar a todas as crianças, independentemente das suas condições físicas, sociais, linguísticas ou outras”. (1994). E afirmar que as escolas devem adequarse às necessidades de todas as crianças significa repensar toda a sua estrutura organizacional, suas relações de tempo-espaço, seu saber-fazer. Enfim, uma ressignificação de práticas de maneira a descolar a instituída adaptação dos estudantes à escola para a instituinte adaptação da escola aos estudantes. E esse fenômeno passa centralmente pela organização escolar.

Nas palavras de Adorno, é preciso 'desbarbarizar' a escola democratizando-a. Como pensar em espaço democrático onde o coletivo e a participação não se constituem? Pensar que os estudantes é que devem adaptar-se à escola é barbarizá-la, é torná-la um espaço apenas para adaptação, é assumi-la como instância unicamente para a reprodução das contradições da sociedade burguesa de classes, é a materialização da 'pseudoformação'.

A concepção de barbárie em Adorno (1995) significa:

A tese que gostaria de discutir é a de que desbarbarizar tornou-se a questão mais urgente da educação hoje em dia. O problema que se impõe nesta medida é saber se por meio da educação pode-se transformar algo de decisivo em relação à barbárie. Entendo por barbárie algo muito simples, ou seja, que, estando na civilização do mais alto desenvolvimento tecnológico, as pessoas se encontrem atrasadas de um modo peculiarmente disforme em relação a sua própria civilização. [...] Considero tão urgente impedir isto que eu reordenaria todos os outros objetivos educacionais por esta prioridade. 
E considerando que desbarbarizar é um objetivo educacional da maior prioridade, é que fundamentamos a importância de se pensar as estruturas organizacionais antidemocráticas vigentes nas escolas contemporâneas brasileiras, tendo em destaque neste estudo o desafio de se organizar as escolas democráticas por intermédio de seus Projetos Pedagógicos.

\section{Organização escolar e cultura organizacional: dimensóes do Projeto Pedagógico}

Até aqui os argumentos trazidos ao debate sobre a organização escolar consideraram apenas os elementos formais (documentos oficiais, dispositivos legais, entre outros) presentes nesse processo. Contudo, nem todos os agentes que atuam na organização escolar podem ser encontrados no próprio processo. Sobre essa afirmativa, Libâneo (2008) destaca que:

\footnotetext{
As organizações, todavia, sofrem forte impacto dos elementos informais - a organização informal, que diz respeito aos comportamentos, às opiniões, às ações e às formas de relacionamento que surgem espontaneamente entre os membros do grupo. Esses aspectos da organização informal têm sido denominados de cultura organizacional.
}

Como podemos observar no pensamento de Libâneo, as forças que agem e derivam do processo de organização escolar não encontram sua gênese apenas na sistemática da própria organização. Isso justifica a preocupação em se criar a expressão 'cultura organizacional' como forma de se traduzir o conjunto de elementos que são capazes de influenciar o processo formal de organização da escola.

Contudo, em relação à ideia de cultura na sociedade, é possível a crítica à formação que tende à banalização sob a égide da heteronomia. Ou seja, a ideia de cultura organizacional da escola não pode ser entendida alienada da ideia de 'cultura de massas' da sociedade contemporânea, pois segundo Adorno (1996):

\footnotetext{
A formação cultural agora se converte em uma semiformação socializada, na onipresença do espírito alienado, que, segundo sua gênese e seu sentido, não antecede à formação cultural, mas a sucede. Deste modo, tudo fica aprisionado nas malhas da socialização [...] Apesar de toda ilustração e de toda informação que se difunde (e até mesmo com sua ajuda) a semiformação passou a ser a forma dominante da consciência atual, o que exige uma teoria que seja abrangente. Para esta teoria, a ideia de cultura não pode ser sagrada - o que a reforçaria como semiformação -, pois a formação nada mais é que a cultura tomada pelo lado de sua apropriação subjetiva.
}

Nesse sentido, a concepção de 'cultura organizacional' deve assumir a dimensão opositiva à banalização que se reforça no discurso dominante da 'cultura de massas', isto é, a cultura organizacional pode se configurar em um redimensionamento in loco da cultura de massas. Para 
tanto, precisa opor-se à ideologia presente na sociedade, para que não reproduza os mecanismos de exclusão e segregação, como por exemplo, os voltados aos estudantes com necessidades especiais.

Em relação às experiências no âmbito do atendimento às necessidades especiais dos estudantes, Peças (2003) reforça a necessidade de se pensar novas formas de cultura organizacional que atendam aos arranjos escolares contemporâneos:

A escola inclusiva reivindica uma matriz cultural e uma cultura organizacional. Não se reduz a uma técnica, a um método; [...] A escola acolhedora funda-se neste paradigma: o de escola como organização de aprendizagem para todos. Neste entendimento reforçam-se dois sentidos indissociáveis para os sujeitos principais do encontro educativo: os alunos todos vão à escola para aprender; os professores são organizadores de ambiências de aprendizagem fecunda para todos.

Assim, salienta-se tanto o papel dos indivíduos como da própria cultura como conjunto de valores e conhecimentos na organização das escolas. Esse aspecto reforça o defendido anteriormente, ou seja, de que uma cultura social que favoreça um estado heterônomo também contribuirá para uma organização escolar igualmente heterônoma composta por pessoas que agem heteronomamente.

Dessa forma, problematizamos: o que pensar da cultura organizacional da escola inserida em um contexto onde a cultura social tem um modus operandi excludente e marginalizador como a sociedade de classes?

Nessa perspectiva, Libâneo (2008), ao analisar a cultura organizacional da escola, esclarece:

Destacar a cultura organizacional como um conceito central na análise da organização das escolas significa buscar a relação das práticas culturais dos indivíduos e sua subjetividade com sua influência nas formas de organização e gestão escolar. Se determinada organização tem como uma de suas características básicas a relação interpessoal, tendo em vista a realização de objetivos comuns, torna-se relevante considerar a subjetividade dos indivíduos e o papel da cultura em determiná-la.

Considera-se assim indissociável os aspectos culturais e os organizacionais. Negar tal aproximação significaria alienar o próprio processo de organização escolar. Isso no pensamento de Adorno (1996) é posto como sendo:

O entendido e experimentado medianamente - semi-entendido e semi-experimentado - não constitui o grau elementar da formação, e sim seu inimigo mortal. Elementos que penetram na consciência sem fundir-se em sua continuidade, se transformam em substância tóxica e, tendencialmente, em superstições, até mesmo quando as criticam [...]. Elementos formativos inassimilados fortalecem a reificação da consciência que deveria justamente ser extirpada pela formação. 
Assim, Adorno nos permite refletir sobre a organização de mundo, de sociedade e até da escola que temos, para além das aparências. Portanto, podemos afirmar que os processos de exclusão que se manifestam também na ausência/escassez de propostas inclusivas nas organizações escolares não são neutros. Revelam a concepção de diferença e o entendimento de diversidade assumido como ideais totalitários na sociedade de 'iguais', ou seja, homogeneizadora.

Dessa forma, várias dimensões sobre concepção de homem, sociedade, formação e educação são percebidas ao refletirmos sobre a organização escolar tal como se apresenta na atualidade. Reforçando as ideias de Adorno, a de que uma sociedade democrática somente seria possível de ser pensada por pessoas livres das amarras ideológicas do sistema social que tende a dirigi-las para a heteronomia, esse pensamento também é comungado por Libâneo (2008), ao afirmar:

\begin{abstract}
A bagagem cultural dos indivíduos contribui para definir a cultura organizacional da organização de que fazem parte. Isso significa que as organizações - a escola, a família, a empresa, o hospital, a prisão, etc. - vão formando uma cultura própria, de modo que os valores, as crenças, os modos de agir dos indivíduos e sua subjetividade são elementos essenciais para compreender a dinâmica interna delas. A cultura organizacional de uma escola explica, por exemplo, o assentimento ou a resistência ante as inovações, certos modos de tratar os alunos, as formas de enfrentamento de problemas de disciplina, a aceitação ou não de mudanças na rotina de trabalho.
\end{abstract}

Dessa maneira, o acompanhamento do processo de elaboração/implementação/ avaliação dos Projetos Pedagógicos em instituições escolares com propostas de atendimento à diversidade nas demandas dos estudantes com necessidades especiais, muito tem a revelar sobre a cultura organizacional da escola e, quem sabe, sobre os aspectos sociais revelados nas práticas escolares.

Assim, longe de enclausurar em uma definição o conceito de cultura organizacional, mas na tentativa de aproximação de uma concepção mais genuína possível de maneira a considerá-la como possibilidade de construção, nos referenciamos a Libâneo (2008), o qual afirma que a cultura organizacional:

[...] pode, então, ser definida como um conjunto de fatores sociais, culturais e psicológicos que influenciam os modos de agir da organização como um todo e o comportamento das pessoas em particular. Isso significa que, além daquelas diretrizes, normas, procedimentos operacionais e rotinas administrativas que identificam as escolas, há aspectos de natureza cultural que as diferenciam umas das outras, não sendo a maior parte deles nem claramente perceptíveis nem explícitos.

Ainda, é Libâneo (2008) quem esclarece o movimento instituinte que constitui o processo de organização escolar considerando a (res)significação de práticas cotidianas:

É importante considerar que a cultura organizacional aparece de duas formas: como cultura instituída e como cultura instituinte. A cultura instituída refere-se às normas legais, à estrutura organizacional definida pelos órgãos oficiais, às rotinas, à grade curricular, aos horários, às normas disciplinares, etc. A cultura instituinte é aquela que os membros da escola criam, 
recriam, em suas relações e na vivência cotidiana. Cada escola tem, pois, uma cultura própria que possibilita entender muitos acontecimentos de seu cotidiano. Essa cultura, porém, pode ser modificada pelas pessoas, pode ser discutida, avaliada, planejada, num rumo que responda mais de perto aos interesses e às aspiraçôes da equipe escolar, o que justifica a formulação conjunta do projeto pedagógico-curricular, a gestão participativa, a construção de uma comunidade de aprendizagem.

Portanto, reiteramos o movimento instituinte apontado por Libâneo, que é a construção coletiva do Projeto Pedagógico. É a possibilidade de criar, recriar, transformar, mudar, superar práticas e propostas no locus escolar. Daí sua característica de instituinte. Assim, é possível afirmar que o Projeto Pedagógico é um reflexo da cultura organizacional da escola. Ou seja, negligenciar que os elementos constituintes da cultura organizacional escolar agem e derivam no processo de elaboração/implementação/avaliação dos Projetos Pedagógicos é aliená-lo no/do processo de organização da escola.

Libâneo (2008), em consonância com Adorno, reforça a ideia de entendimento local da organização escolar tendo como elementos de reflexão os agentes macrossociais, os quais, muitas vezes, além de condicionantes são determinantes nas formas de ser/estar a/na escola contemporânea:

\footnotetext{
Entretanto, essa maneira de ver a organização escolar precisa considerar o contexto concreto e real das interações sociais - marcado, também, por conflitos, por relações de poder externas e internas, por interesses pessoais e políticos - assim como os próprios objetivos sociais e culturais definidos pela sociedade e pelo estado.
}

E ainda se aproxima do pensamento de Adorno no que se refere à reprodução de práticas instituídas socialmente pela escola. Isso é possível de ser afirmado quando destaca (2008):

[...] de um lado, a organização como uma construção social envolvendo a experiência subjetiva e cultural das pessoas; de outro, essa construção não como um processo livre e voluntário, mas mediatizado pela realidade sociocultural e política mais ampla, incluindo a influência de forças externas e internas marcadas por interesses de grupos sociais sempre contraditórios e, às vezes, conflituosos.

Ou seja, na percepção de Libâneo, fica clara a ideia de que a escola é um espaço de disputas, de luta entre visões e concepções de homem e mundo. Dessa forma, ao se projetar no movimento de organização da escola com base em Projetos Pedagógicos emancipatórios, considerando a cultura organizacional social e local de cada escola, está posta a luta que se constituirá como a possibilidade de superação dos atavismos que aprisionam as práticas pedagógicas historicamente segregadoras e portanto, proporcionalmente desumanas. 
Considerações finais: Projeto Pedagógico como movimento instituinte na organização da escola Segundo Libâneo (2008):

O processo de organização escolar dispõe, portanto, de funções, propriedades comuns ao sistema
organizacional de uma instituição, com base nas quais se definem ações e operações necessárias
ao funcionamento institucional. São quatro as funçôes constitutivas desse sistema:
a) planejamento: explicitação de objetivos e antecipação de decisões para orientar a instituição,
prevendo o que se deve fazer para atingi-los;

b) organização: racionalização de recursos humanos, físicos, materiais, financeiros, criando e viabilizando as condiçôes e modos para realizar o que já foi planejado;

c) direção/coordenação: coordenação do esforço humano coletivo do pessoal da escola;

d) avaliação: comprovação e avaliação do funcionamento da escola.

O que analisamos frente ao pensamento de Libâneo é que o processo de organização apresenta uma sistemática que cria uma estrutura dando sustentabilidade ao que se pretende organizar, no caso o trabalho escolar. Considerando as funções constitutivas do sistema de organização escolar problematizadas pelo autor, identificamos que a de planejamento possui relação mais íntima com nosso objeto de estudo.

Recorrendo ao seu pensamento novamente (LIBÂNEO, 2008) encontramos os subsídios teóricos que reforçam essa aproximação entre planejamento e Projeto Pedagógico:

O planejamento consiste em ações e procedimentos para tomada de decisões a respeito de objetivos e de atividades a ser realizadas em razão desses objetivos. É um processo de conhecimento e de análise da realidade escolar em suas condições concretas, tendo em vista a elaboração de um plano ou projeto para a instituição. O planejamento do trabalho possibilita uma previsão de tudo o que se fará com relação aos vários aspectos da organização escolar e prioriza as atividades que necessitam de maior atenção no ano que ele se refere. Assim, podem ser distribuídas as responsabilidades a cada setor da escola e aos membros da equipe.

Ou seja, é objetiva a relação entre planejamento e Projeto Pedagógico. Na verdade, o segundo é constituído a partir do primeiro. Pelo planejamento, que imbuído de um caráter democratizador deverá ser elaborado participativamente, com a contribuição de todos os interessados na ação educativa (equipe gestora, docentes, discentes e comunidade), os contextos diversos que compõem a realidade escolar local integrarão o cenário onde as direções assumidas pelo coletivo devem empregar seus esforços.

Assim, no que se refere ao planejamento das ações e procedimentos que devem compor os objetivos de (re)organização com vistas à democratização escolar, considerando o atendimento das necessidades especiais dos estudantes que irão constituir o plano de ação denominado Projeto Pedagógico, é resultado de um longo processo de investigação das demandas advindas do educar na/para a diversidade. Nesse sentido, Libâneo (2008) reforça que: 
Toda organização precisa de um plano de trabalho que indique os objetivos e os meios de sua execução, superando a improvisação e a falta de rumo. A atividade de planejamento resulta, portanto, naquilo que aqui denominamos de projeto pedagógico-curricular. $\mathrm{O}$ projeto é um documento que propõe uma direção política e pedagógica para o trabalho escolar, formula metas, prevê ações, institui procedimentos e instrumentos de ação.

Em sendo o Projeto Pedagógico a materialização do planejamento, possui vital importância no processo de organização da escola. A questão da dimensão instituinte dos Projetos Pedagógicos, fundamentada no pensamento dos autores que dão sustentação teórica a este estudo, contribui na compreensão das escolhas pedagógicas que balizam esses projetos. Sobre a característica eminentemente pedagógica dos chamados por Libâneo (2008) Projetos PedagógicoCurriculares, destacamos:

É pedagógico porque formula objetivos sociais e políticos e meios formativos para dar uma direção ao processo educativo, indicando por que e como se ensina e, sobretudo, orientando o trabalho educativo para as finalidades sociais e políticas almejadas pelo grupo de educadores. O projeto expressa, pois, uma atitude pedagógica, que consiste em dar um sentido, um rumo, às práticas educativas, onde quer que sejam realizadas, e firmar as condições organizativas e metodológicas para a viabilização da atividade educativa.

Reafirmamos aqui a questão central deste estudo. O processo de elaboração/implementação/ avaliação do Projeto Pedagógico da escola com proposta inclusiva revela questões centrais em termos de sua organização para o atendimento das necessidades educacionais dos seus estudantes, como por exemplo: o que vem sendo entendido por inclusão escolar na contemporaneidade? Para que incluímos estudantes com necessidades especiais nas escolas regulares? Uma vez que atualmente está ocorrendo inclusão de estudantes com necessidades especiais, como está se dando esse atendimento na escola? De que maneira as articulações locais escolares possibilitam $\mathrm{o}$ atendimento às necessidades especiais dos estudantes?

Percebemos que essas questões são contextuais. Portanto, configuram um cenário que os Projetos Pedagógicos deverão considerar e não poderão ser negadas se realmente estiverem no cerne da (re)organização da escola sua democratização e atendimento à diversidade. Longe de concluir, mas ainda reconhecendo a necessidade de reafirmação da importância dos Projetos Pedagógicos para instituição de novas formas de ser/fazer a escola, Libâneo (2008) reitera:

Deve-se salientar que o projeto pedagógico-curricular é um documento que reproduz as intenções e o modus operandi da equipe escolar, cuja viabilização necessita das formas de organização e de gestão. Não basta ter o projeto, é preciso que seja levado a efeito. As práticas de organização e de gestão executam o processo organizacional para atender o projeto. 
Assim, é evidente a importância do Projeto Pedagógico escolar, uma vez que constituída a dinâmica que se formalizará em um documento, todo o processo organizacional se desenvolverá considerando as escolhas que foram/são realizadas por ocasião de sua elaboração/implementação/ avaliação.

Não resta dúvida de que a dinâmica dos Projetos Pedagógicos das escolas, que na atualidade vem se organizando como inclusivas, muito tem a revelar sobre qual inclusão está sendo possível nesse momento histórico da educação escolar brasileira.

\section{REFERÊNCIAS}

ADORNO, T. W. Educação e emancipação. São Paulo: Paz e Terra, 1995.

. Palavras e Sinas: Modelos Críticos 2. Petrópolis, RJ: Vozes, 1995 a.

dez. 1996.

. Teoria da Semicultura. Educação e Sociedade. Campinas: Papirus, ano XVII,

BRASIL. Política Nacional de Educação Especial na Perspectiva da Educação Inclusiva. Brasília: MEC/SEESP, 2008.

COSTA, V. A. da. Políticas públicas de formação de professores: questões acerca da inclusão escolar, educação e diversidade. In: Cadernos de Ensaios e Pesquisa. Niterói, FEUFF, Ano 4, Caderno 9. Julho 2003/Junho 2004.

Formação e Teoria Crítica da Escola de Frankfurt: trabalho, educação, indivíduo com deficiência. Niterói, EdUFF, 2005.

. Os processos de inclusão dos alunos com necessidades educativas especiais: políticas e sistemas. Rio de Janeiro: UNIRIO/CEAD, 2007.

DAMASCENO, A. R. A formação dos professores e os desafios para a educação inclusiva: as experiências da escola Municipal Leônidas Sobriño Pôrto. Dissertação de Mestrado apresentada ao Programa de Pós-Graduação em Educação, Universidade Federal Fluminense, 2006.

GLAT, R. \& BLANCO, L. de M. V. Educação Especial no contexto de uma educação inclusiva. In: GLAT, R. (org.). Educação inclusiva: cultura e cotidiano escolar. Rio de Janeiro: 7 letras, 2007.

LIBÂNEO, J. C. Organização e gestão da escola: teoria e prática. 5. ed. Goiânia: Editora Alternativa, 2004.

; OLIVEIRA, J. F. de. \& TOSCHI, M. S. Educação escolar: políticas, estrutura e organização. 6. ed., São Paulo: Cortez, 2008. 
MEC, INEP, 2009. Publicados resultados preliminares do Censo Escolar da Educação Básica 2009. Disponível em: http://www.inep.gov.br/imprensa/noticias/censo/escolar/ news09_09.htm Acessado em: outubro 2009.

MELETTI, S. M. F. \& BUENO, J. G. S. Escolarização de alunos com deficiência: uma análise dos indicadores sociais no Brasil (1997-2006). In: 33ª Reunião Anual da ANPED. Caxambu: ANPED, 2010.

PEÇAS, A. Uma escola acolhedora, uma educação inclusiva. In: Compartilhando o mundo com Paulo Freire. LINHARES, C. \& TRINDADE, M. de N. (orgs.). São Paulo: Cortez, 2003.

UNESCO. Declaração Mundial sobre Educação para Todos: Plano de Ação para satisfazer as Necessidades Básicas de Aprendizagem. Brasília, CORDE, 1990.

Declaração de Salamanca e suas Linhas de Ação sobre Necessidades Educativas Especiais. Brasília, CORDE, 1994.

Submetido em: 04/2012

Aprovado em: 06/2012 